\title{
Female dietary patterns and outcomes of in vitro fertilization (IVF): a systematic literature review
}

\author{
Elizabeth A. Sanderman ${ }^{1 *} \mathbb{D}$, Sydney K. Willis ${ }^{2}$ and Lauren A. Wise ${ }^{2}$
}

\begin{abstract}
Background: Infertility affects up to $15 \%$ of couples. In vitro fertilization (IVF) treatment has modest success rates and some factors associated with infertility and poor treatment outcomes are not modifiable. Several studies have assessed the association between female dietary patterns, a modifiable factor, and IVF outcomes with conflicting results. We performed a systematic literature review to identify female dietary patterns associated with IVF outcomes, evaluate the body of evidence for potential sources of heterogeneity and methodological challenges, and offer suggestions to minimize heterogeneity and bias in future studies.

Methods: We performed systematic literature searches in EMBASE, PubMed, CINAHL, and Cochrane Central Register of Controlled Trials for studies with a publication date up to March 2020. We excluded studies limited to women who were overweight or diagnosed with PCOS. We included studies that evaluated the outcome of pregnancy or live birth. We conducted an initial bias assessment using the SIGN 50 Methodology Checklist 3.

Results: We reviewed 3280 titles and/or titles and abstracts. Seven prospective cohort studies investigating nine dietary patterns fit the inclusion criteria. Higher adherence to the Mediterranean diet, a'profertility' diet, or a Dutch 'preconception' diet was associated with pregnancy or live birth after IVF treatment in at least one study. However, causation cannot be assumed. Studies were potentially hindered by methodological challenges (misclassification of the exposure, left truncation, and lack of comprehensive control for confounding) with an associated risk of bias. Studies of the Mediterranean diet were highly heterogenous in findings, study population, and methods. Remaining dietary patterns have only been examined in single and relatively small studies.
\end{abstract}

Conclusions: Future studies with rigorous and more uniform methodologies are needed to assess the association between female dietary patterns and IVF outcomes. At the clinical level, findings from this review do not support recommending any single dietary pattern for the purpose of improving pregnancy or live birth rates in women undergoing IVF treatment.

Keywords: Dietary patterns, Diet, IVF, In vitro fertilization, Assisted reproductive technology, ART, Infertility, Fertility, Female, Maternal

*Correspondence: elizabeth.sanderman@gmail.com

${ }^{1}$ Boston College, Boston, USA

Full list of author information is available at the end of the article

\section{Background}

Approximately $15 \%$ of couples in the United States and one in four couples in developing countries are affected by infertility, defined as the inability to become pregnant after 12 months of regular unprotected intercourse [1, 2]. The World Health Organization recognizes infertility treatment and the examination of factors associated 
with fertility as essential to the promotion of reproductive health $[1,3]$.

Though in vitro fertilization (IVF) is one of the most effective treatments for infertility [4], much of the success of IVF relies on women undergoing multiple embryo transfers and oocyte retrievals. However, multiple embryo transfers and oocyte retrievals can be cost prohibitive and emotionally and physically burdensome resulting in reported treatment attrition rates of up to $35-50 \%[5,6]$. While some factors associated with lower success of IVF treatment, such as advanced female age, are not modifiable, there is growing interest in the impact of modifiable factors, such as diet, on treatment outcomes.

Diet currently accounts for nearly a tenth of the global burden of disease $[7,8]$ and epidemiological studies have linked female and male diet to reproductive outcomes. Studies on the general impact of diet on female fertility have focused largely on the examination of specific dietary nutrients and food groups, such as dairy, fats, and antioxidants, and point to several different potential pathways of effect. Animal and in vitro human cell studies indicate possible associations with mechanisms that underlie fertility including hormone levels, ovarian insufficiency, diminished ovarian reserve, and embryonic development [9-15]. Human studies link dietary factors to longer time to pregnancy and the risk of developing reproductive disorders which may impact fertility such as anovulatory infertility, endometriosis, and uterine leiomyomata [16-29]. However, despite uncovering possible links with fertility and fecundity, studies of associations between individual female dietary factors and infertility in both animals and humans are largely equivocal.

Much of what is known about the impact of individual female dietary factors specifically on IVF outcomes derives from a single observational study, the study of Environment And Reproductive Health (EARTH), described in detail elsewhere [30-32]. Within the context of IVF, female dietary patterns have been more widely studied. This reflects a trend toward viewing diet holistically in an effort to limit confounding from individual dietary items, capturing the effects resulting from the complex interactions between food groups, and providing results that are more interpretable and translatable to individuals [33-35].

To date, studies on associations between female dietary patterns and IVF outcomes have relied on observational designs. While randomized controlled trials are the gold standard for research methods, observational designs can be appropriate when the exposure is a dietary pattern; blinding may not be possible, ensuring adherence can be difficult, and participants may need to remain in a trial for long periods of time to observe the effect [36].
However, observational studies are often hindered by methodological challenges that carry the risk for bias, such as exposure misclassification, confounding control, and cohort selection. Further, observational studies are often carried out in populations and employ methods that are considerably different, necessitating careful consideration of heterogeneity across studies when comparing findings or pooling results $[37,38]$.

Given the importance of understanding the associations between diet, including dietary patterns, and IVF outcomes, the observational nature of existing studies, and the need to compare and conduct well-designed epidemiologic studies, we performed a systematic literature review with the following aims: to identify female dietary patterns associated with the outcomes of IVF treatment, to evaluate the body of evidence for sources of heterogeneity and methodological challenges, and to offer suggestions for minimizing heterogeneity and potential sources of bias in future studies.

\section{Methods}

This review follows the Preferred Reporting Items for Systematic Reviews and Meta-Analysis (PRISMA) guidelines [39] (Supplemental Table 1).

\section{Search strategy}

Articles were identified through computerized literature searches undertaken March-April 2020. We searched PubMed, EMBASE, Cochrane Central Register of Controlled Trials, and CINAHL for English language publications. In EMBASE we utilized key words and EMTREE terms: 'infertility' OR ('in vitro fertilization' OR 'infertility therapy' OR 'IVF') AND ('dietary intake' OR 'diet' OR 'dietary pattern'). In PubMed we utilized MeSH terms and keywords: ('IVF' OR 'in vitro fertilization') OR ('reproductive techniques, assisted' OR 'assisted reproductive technology') and ('food OR diet'). Finally, we performed a manual search of the reference lists from the final included articles.

\section{Selection criteria}

Inclusion criteria were based on the PICO framework (Population, Intervention, Comparison, Outcome) [39]. P: women undergoing IVF or IVF with intracytoplasmic sperm injection (ICSI). Weight loss potentially improves outcomes during IVF treatment among women who are overweight (body mass index $>=25 \mathrm{~kg} / \mathrm{m} 2$ ) or diagnosed with polycystic ovarian syndrome (PCOS) [40]; thus, we excluded studies restricted to women who are overweight or diagnosed with PCOS. I: dietary pattern with clearly delineated component food items. C: comparison group that differed in adherence to the dietary pattern. Early outcomes, such as embryo quality and yield, 
may not predict overall IVF treatment success [41-43]. Thus O: biochemical pregnancy (pregnancy diagnosed only by the detection of beta human chorionic gonadotrophin ( $\beta \mathrm{hCG}$ ) in serum or urine), clinical pregnancy (pregnancy diagnosed by ultrasonographic visualization of one or more gestational sacs or definitive clinical signs of pregnancy), or live birth (the birth of a live fetus after 22 completed weeks of gestational age) [44].

We included peer reviewed original research articles with a publication date up to March 1, 2020. Review articles, editorials, conference abstracts, opinions, and case reports were excluded.

\section{Assessment of study quality}

The SIGN 50 Methodology Checklist 3 [45], a checklist specific to observational studies, was utilized to assess study quality. Studies were rated as "high quality" if the majority of criteria in the checklist were met and there is little risk of bias, "acceptable" if most criteria were met with some flaws and an associated risk of bias and "low quality" if either most criteria were not met or if there were significant flaws in the study design. One of the aims of this review is to explore methodological challenges in some depth. However, an initial assessment of studies was conducted to eliminate studies that did not receive a rating of "acceptable" or higher.

\section{Data extraction}

One author extracted data from the included studies and another subsequently confirmed or disconfirmed the data. Investigators from five studies were contacted for clarification. We extracted study characteristics: first author, year of publication, location, study duration, study design (observational vs. interventional; and crosssectional, case-control, cohort), and analytical sample size. We extracted sample characteristics: age, major exclusions, infertility diagnosis, type of ART (IVF vs IVF/ ICSI), prior ART treatment, number of prior failed pregnancy attempts, and 'duration of infertility'. We extracted data on the exposure (dietary pattern, exposure window), methods (questionnaire used for assessing exposure, timing of recruitment and exposure assessment, covariates, study end points, follow up period), and how outcomes were defined (Supplemental Table 2).

\section{Results}

\section{Search results}

The search of databases identified 5308 English language references (Fig. 1). After removal of duplicates, 3280 articles remained. We screened remaining references by reading titles and/or titles and abstracts; 3215 articles were deemed not relevant. We scanned the full texts of the remaining 65 articles and identified 56 for exclusion:
12 were reviews, opinions, or conference abstracts and 2 could not be located. 42 did not meet PICO criteria. Nine articles, representing nine independent research studies reporting on female dietary patterns and IVF outcomes, remained. No additional articles were identified after scanning reference lists.

\section{Assessment of study quality}

Nine studies underwent the initial quality assessment and two studies were omitted; one lacked sufficient information to make an assessment [46] and one contained a measure of association for clinical pregnancy that fell outside the confidence interval (OR 0.14, 95\% CI: 0.3-0.7) [47]. Study authors could not be reached to correct this error [47] (Table 1). Seven studies were rated as "acceptable" quality and were included in the review. In included studies, potential selection bias and reliability of exposure assessment were the most common inadequately addressed items (items 1.2, 1.3, 1.4, 1.5, 1.6, 1.12, Table 1).

\section{Dietary patterns associated with IVF outcomes}

Nine dietary patterns were examined for an association with IVF outcomes in seven observational cohort studies: the MedDiet (Mediterranean diet and a 'Mediterranean style' dietary pattern), a Dutch 'preconception' diet, a 'profertility' diet, the 'Fertility Diet', the alternate Healthy Eating Index 2010 (aHEI-2010) diet, and the 'health-conscious low processed,' 'vegetable and seafood,' 'Western', and 'rice and miso soup' dietary patterns (Table 2).

\section{Mediterranean diet}

The MedDiet is generally comprised of high intake of whole grains, vegetables, fruits, nuts, legumes and/or pulses, and olive oil; moderate intake of nonfat or low-fat dairy products, seafood, and wine; and low consumption of poultry and red meat [55-57] (Table 2). In all five studies examining the MedDiet, participants were recruited from IVF treatment centers, had their diet assessed using a questionnaire at a point prior to embryo transfer, and followed prospectively.

Four studies examined the outcome biochemical pregnancy (Table 3). In a study of 161 couples in the Netherlands, Vujkovic (2010) reported a positive association between a positive urine pregnancy test 15 days after oocyte retrieval, and a couple's increased adherence to a 'Mediterranean style' dietary pattern (adjusted OR 1.4, 95\% CI: 1.0-1.9). Study participants were assigned an individual diet adherence score based on their responses to a food frequency questionnaire (FFQ). The scores from both members of the couple were then averaged and used as the exposure. No analysis was conducted to decipher associations of female or male diet alone with 


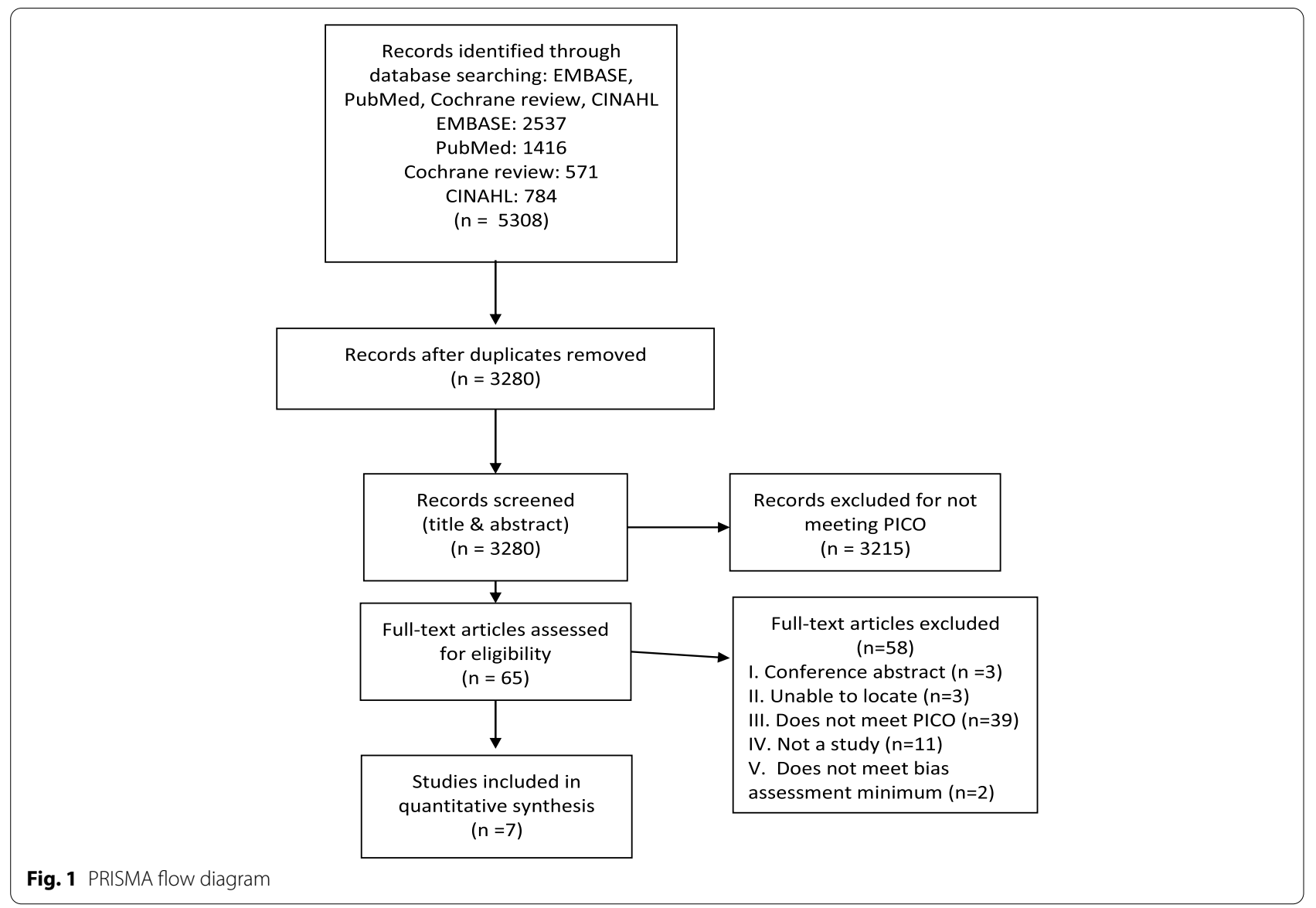

biochemical pregnancy. Biochemical pregnancy was the only examined pregnancy related outcome in this study and no appreciable association with biochemical pregnancy was found in any other study of the MedDiet [48, $49,52]$.

Four studies examined associations with clinical pregnancy $[48-50,52]$ (Table 3 ). In a study conducted in a Greek population with 244 women, Karayiannis (2018) reported a positive association between high adherence to the MedDiet (as a continuous variable) and clinical pregnancy in women under the age of 35 (adjusted RR 1.2, 95\% CI: 1.05-1.43). Findings were not consistent among older women (adjusted RR 1.00, 95\% CI: 0.921.09). In a study of 474 Italian women, Ricci (2019) found an association between lower adherence to the MedDiet and risk of not achieving a clinical pregnancy however, contrary to Karayiannis (2018), the association was only present among older women aged $\geq 35$ years. Further, among older women, the association was found only in the intermediate versus lower MedDiet adherence categories (adjusted RR 0.84, 95\% CI: 0.71-1.01) and not present in the highest versus lower adherence categories (adjusted RR 0.94, 95\% CI: 0.78-1.13). No other study found an appreciable association with clinical pregnancy $[48,52]$.

Three studies examined associations between the MedDiet and live birth [48-50] (Table 3). Gaskins and colleagues (2019) reported a positive association between the MedDiet and the probability of live birth in a sample of 357U.S. women. There was not a dose-response association and the association was only present when comparing the lowest level of adherence to an intermediate level of adherence (probability of live birth as an adjusted proportion $(95 \% \mathrm{CI})$ in increasing quartiles of adherence $=0.31(0.25-0.39), 0.47(0.39-0.55), 0.44$ (0.36-0.49), 0.41 (0.34-0.49). Karayiannis (2018) found a positive association between increased adherence to the MedDiet (as a continuous variable) and live birth. Mirroring the study's results for clinical pregnancy, the association was only among women under age 35 years (adjusted RR 1.25, 95\% CI: 1.07-1.45). Ricci and colleagues (2019) reported no association with live birth in any age or dietary adherence group.

In a study conducted in China, Sun (2019) observed that clinical pregnancy rates in a high versus low adherence group was $42.62 \%$ vs. $50.94 \%$ and biochemical 


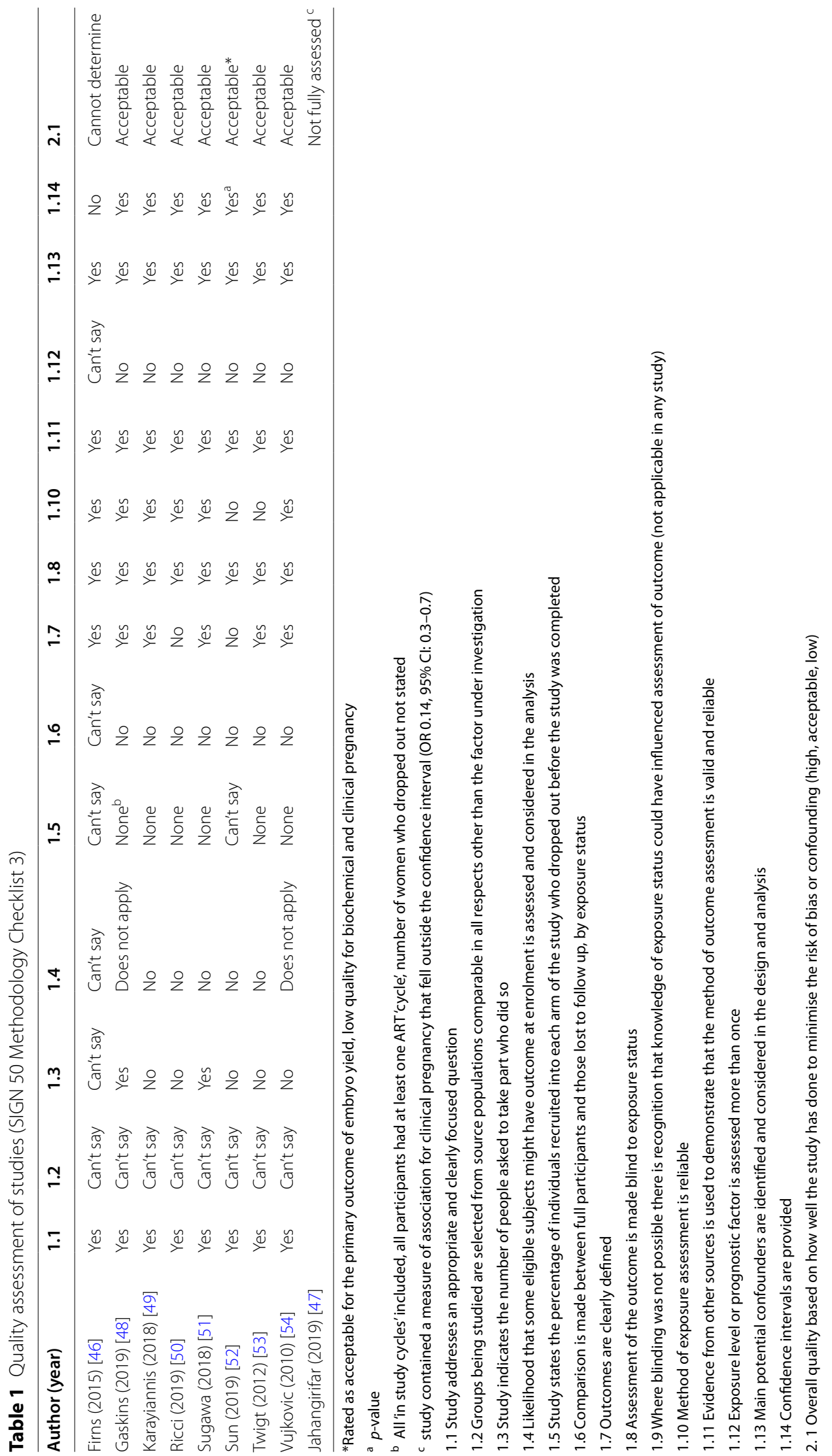


Table 2 Components of dietary patterns

\begin{tabular}{|c|c|c|c|c|c|c|c|c|c|}
\hline Dietary fact & $\begin{array}{l}\text { Mediterranean } \\
\text { Diet }\end{array}$ & $\begin{array}{l}\text { Healthy } \\
\text { Eating } \\
\text { Index } \\
\text { (aHEI2010) }\end{array}$ & $\begin{array}{l}\text { Fertility } \\
\text { Diet }\end{array}$ & $\begin{array}{l}\text { profertility } \\
\text { diet }\end{array}$ & $\begin{array}{l}\text { rice and } \\
\text { miso }\end{array}$ & $\begin{array}{l}\text { vegetable } \\
\text { and } \\
\text { seafood }\end{array}$ & $\begin{array}{l}\text { 'Western' } \\
\text { Diet }\end{array}$ & $\begin{array}{l}\text { preconception } \\
\text { diet }\end{array}$ & $\begin{array}{l}\text { health } \\
\text { conscious }\end{array}$ \\
\hline Seafood & + & & & + & & + & - & + & + \\
\hline Legumes & + & + & & & & & & & + \\
\hline Fruit & $+{ }^{k}$ & + & & $+/-^{i}$ & & & & + & + \\
\hline Vegetables & + & + & + & $+/-^{i}$ & & + & & + & + \\
\hline Potatoes & $+{ }^{b}$ & & & & & & & & \\
\hline Dairy & $-e$ & & $+/-^{h}$ & + & & & & & \\
\hline Cereal & $++^{c}$ & + & & $+^{\mathrm{j}}$ & & & & $+^{j}$ & $+^{\mathrm{j}}$ \\
\hline Fats & $+^{\prime}$ & + & + & & & & $+^{n}$ & + & \\
\hline Soy & & & & + & & + & & & \\
\hline Vitamins & & & + & + & & & & & \\
\hline Nuts & $+^{d}$ & + & & & & & & & \\
\hline Meat & $-f$ & - & - & - & & & $+^{\mathrm{m}}$ & + & - \\
\hline Poultry & -9 & & & & & + & + & & \\
\hline Rice/miso & & & & & + & & & & \\
\hline Alcohol & $t^{\mathrm{a}}$ & + & & & & & & & \\
\hline
\end{tabular}

+ Indicates dietary component is used to calculate the total dietary score and contributes to a higher score

- indicates dietary component is used to calculate the total dietary score and contributes to a lower score

a Sun 2019 [52] did not include alcohol

b Sun 2019 [52] and Vujkovic 2010 [54] did not include potatoes

c Gaskins 2019 [48], Karayiannis 2018 [49] and Sun 2019 [52] specified unrefined or whole grain; Vujkovic 2010 [54] did not include cereal

d Sun 2019 [52] included nuts

e Gaskins 2019 [48] and Karayiannis 2018 [49] specified full fat dairy; Vujkovic 2010 [54] did not include dairy

f Vujkovic 2010 [54] did not included meat, Gaskins 2019 [48] specified red meat

${ }^{9}$ Ricci 2019 [50], Sun 2019 [52], and Vujkovic 2010 [54] did not include or specify poultry

${ }^{\mathrm{h}}$ high fat dairy contributed positively, and low-fat dairy contributed negatively

I low pesticide fruits and vegetables contributed positively, and high pesticide fruits and vegetables contributed negatively low pesticide fruits and vegetables contributed positively and high pesticide fruits and vegetables contributed negatively

j only whole grain cereal

${ }^{k}$ Vujkovic 2010 [54] did not include fruits

I Vujkovic 2010 [54] specified vegetable oil, Ricci 2019 [50] high monounsaturated/saturate fatty acid ratio, Gaskins 2019 [48] and Karayiannis 2018 [49] specified olive oil

m Sugawa 2018 [51] specified red meat

${ }^{\text {n }}$ Sugawa 2018 [51] specified oils

pregnancy rate $27.97 \%$ versus $31.75 \%$ respectively (Table 3). However, out of 590 participants, only 61 women in the high adherence group and 106 in the low adherence group had an embryo transfer by study completion. Reasons for the abbreviated follow up are not given. Results for biochemical pregnancy and clinical pregnancy were only adjusted for endometrial thickness on embryo transfer day and number of embryos transferred.

\section{'Profertility' diet}

The 'profertility' diet was examined alongside the MedDiet in Gaskins 2019. The 'profertility' diet is based on findings from the EARTH study and comprises higher intake of supplemental folic acid, vitamin B12, vitamin $\mathrm{D}$, low-pesticide fruits and vegetables, whole grains, seafood, dairy, and soy foods; and lower intake of high pesticide fruits and vegetables [32, 48] (Table 2). Higher adherence to the 'profertility' diet was positively associated with biochemical pregnancy, clinical pregnancy, and probability of live birth (probability of live birth as an adjusted proportion Q1 vs Q4 $(95 \% \mathrm{CI})=0.33(0.26-$ 0.40), 0.56 (0.47-0.64) (Gaskins, 2019) (Table 4). Findings were largely attributed to intake of micronutrients and pesticide residues on fruits and vegetables, however an indirect approximated measure of pesticide intake was used to assess exposure [48]. The sample included 357 women participating in the EARTH study and the 
Table 3 Associations between higher adherence to the MedDiet and outcomes

\begin{tabular}{|c|c|c|c|c|}
\hline Outcome & Author (year) & Sample size & Main finding & Measure of association \\
\hline \multirow[t]{4}{*}{ Biochemical pregnancy } & Vujkovik (2010) [54] & 161 couples & + & adjusted OR (95\% Cl) (ref not stated): 1.4 (1.0-1.9) \\
\hline & Karayiannis (2018) [49] & 244 women & no appreciable association & $\begin{array}{l}\text { adjusted RR (95\% Cl) Q1-Q3: } 0.62 \text { (0.28-1.36), } 0.81 \\
(0.39-1.65), 1.00 \text { (ref) }\end{array}$ \\
\hline & Gaskins (2019) [48] & 357 women $^{\mathrm{a}}$ & no appreciable association & $\begin{array}{l}\text { adjusted proportion (95\% Cl) Q1-Q4: } 0.49(0.41-0.57) \text {, } \\
0.62(0.53-0.69), 0.64(0.55-0.72), 0.55(0.47-0.63)\end{array}$ \\
\hline & Sun (2019) [52] & 167 women & no appreciable association & $\begin{array}{l}\text { (binary) high adherence }=29.97 \% \text {, low adher- } \\
\text { ence }=31.75 \%\end{array}$ \\
\hline \multirow[t]{4}{*}{ Clinical pregnancy } & Karayiannis (2018) [49] & 244 women & + Age $<35$ years & $\begin{array}{l}\text { adjusted RR (as a continuous variable) }(95 \% \mathrm{Cl}) \text { : } \\
\text { Age }<35 \text { years } 1.22(1.05-1.43) \\
\text { Age } \geq 351.00(0.92-1.09) \\
\text { adjusted RR Q1-Q3 (95\%Cl): all women } 0.35 \text { (0.16-0.78), } \\
0.81 \text { (0.41-1.59), } 1.00 \text { (ref) }\end{array}$ \\
\hline & Gaskins (2019) [48] & 357 women $^{1}$ & no appreciable association & $\begin{array}{l}\text { adjusted proportion (95\% CI) Q1-Q4: } 0.43(0.35-0.50) \text {, } \\
0.56(0.47-0.64), 0.57(0.48-0.66), 0.48(0.40-0.56)\end{array}$ \\
\hline & Ricci (2019) [50] & 474 women & + Age $>35^{b}$ & $\begin{array}{l}\text { adjusted RR of not achieving pregnancy Q1-Q3 (95\% } \\
\text { Cl): Age } \leq 351 \text { (ref), } 0.96(0.80-1.14), 0.99(0.81-1.20) \\
\text { Age }>351 \text { (ref), } 0.84(0.70-1.00), 0.94(0.81-1.20) \\
\text { all women } 1 \text { (ref), } 0.95(0.86-1.05), 0.98(0.87-1.09)\end{array}$ \\
\hline & Sun (2019) [52] & 167 women & no appreciable association & $\begin{array}{l}\text { (binary) high adherence }=42.62 \% \text {, low adher- } \\
\text { ence }=50.94 \%\end{array}$ \\
\hline \multirow[t]{3}{*}{ Live birth } & Karayiannis (2018) [49] & 244 women & + Age $<35$ years & $\begin{array}{l}\text { adjusted RR (as a continuous variable) }(95 \% \mathrm{Cl}) \text { : } \\
\text { Age }<351.25(1.07-1.45) \\
\text { Age } \geq 351.01(0.93-1.11) \\
\text { adjusted RR Q1-Q3 (95\%Cl): all women } 0.32(0.14-0.71), \\
0.78 \text { (0.39-1.54), } 1.00 \text { (ref) }\end{array}$ \\
\hline & Gaskins (2019) [48] & 357 women $^{1}$ & $+{ }^{c}$ & $\begin{array}{l}\text { adjusted proportion (95\% Cl) Q1-Q4: } 0.31(0.25-0.39) \text {, } \\
0.47(0.39-0.55), 0.44(0.36-0.49), 0.41(0.34-0.49)\end{array}$ \\
\hline & $\operatorname{Ricci}(2019)[50]$ & 474 women & Null & $\begin{array}{l}\text { adjusted RR Q1-Q3 }(95 \% \mathrm{Cl}) \\
\text { Age } \leq 351.00 \text { (ref), } 1.00(0.81-1.21), 1.00(0.79-1.26) \\
\text { Age> } 351.00 \text { (ref), } 0.96(0.84-1.10), 0.97(0.84-1.12) \\
\text { all women } 1 \text { (ref), } 1.00(0.90-1.11), 0.99(0.89-1.11)\end{array}$ \\
\hline
\end{tabular}

${ }^{+}=$positive association

a the sample contributed 608 ART'cycles' and adjustments were made for unbalanced study design (different number of cycles contributed per woman)

b positive association for Q2 vs Q1 only

${ }^{\mathrm{c}} \mathrm{Q} 2 \mathrm{vs} \mathrm{Q} 1$ only

'profertility' diet has not been tested in an independent cohort [32, 48]. Gaskins (2019) followed women for multiple cycles (maximum of 6 'cycles') and included all 'in study cycles' in the main analysis. The sample contained a relatively low number of frozen embryo transfer cycles (14\%) versus fresh embryo transfer cycles $(82 \%)$ when compared with recent (2016) U.S. wide treatment trends (33\% frozen embryo transfer cycles versus 33\% fresh embryo transfer cycles [58]).

\section{A Dutch 'preconception' diet}

In a study of 199 Dutch women undergoing IVF treatment, Twigt (2012) found a positive association between increasing adherence to a Dutch 'preconception' diet and ongoing pregnancy at 10 weeks (adjusted OR 1.65, 95\% CI: 1.08-2.52) [53] (Table 4). The Dutch 'preconception' diet is comprised of: high daily intake of whole grains, vegetables, and fruit; weekly intake of at least three servings of meat or meat replacers and one serving of fish; and use of monounsaturated or polyunsaturated oils [53] (Table 2). The study occurred within the context of a preconception intervention in which women attending an outpatient OB/GYN clinic could opt into counseling to improve their lifestyle, including diet. The analytic population comprised women who opted into the intervention and subsequently underwent an IVF treatment. Findings may have different implications from other findings in this review. Participants were given a preconception dietary risk score (PDR) with the highest score corresponding to dietary intake that meets the basic requirements of a preconception diet. Thus, lower PDRs likely represent inadequate dietary intake and any increase in PDR score, a step toward adequacy. Conversely, it is not clear if lower levels of adherence to most other dietary patterns in this review correspond to an inadequate, or merely different, dietary pattern. Exposure was reassessed in $46 \%$ of participants at a voluntary follow up session, however only baseline exposure was used in the analysis. 
Table 4 Associations between higher adherence to dietary patterns and outcomes

\begin{tabular}{|c|c|c|c|c|c|}
\hline Dietary pattern & Outcome & Author & Sample size & Main finding & Measure of association \\
\hline \multirow[t]{3}{*}{ 'profertility' diet } & Biochemical pregnancy & Gaskins (2019) [48] & 357 women $^{\mathrm{a}}$ & + & $\begin{array}{l}\text { adjusted proportion Q1-Q4 } \\
(95 \% \mathrm{Cl}): 0.46(0.39-0.54), 0.53 \\
(0.45-0.61), 0.65(0.56-0.73), \\
0.68(0.59-0.76)\end{array}$ \\
\hline & Clinical pregnancy & Gaskins (2019) [48] & 357 women $^{\mathrm{a}}$ & + & $\begin{array}{l}\text { adjusted proportion Q1-Q4 } \\
(95 \% \mathrm{Cl}): 0.44(0.33-0.48), 0.46 \\
(0.38-0.54), 0.59(0.50-0.68), \\
0.61(0.52-0.69)\end{array}$ \\
\hline & Live birth & Gaskins (2019) [48] & 357 women $^{a}$ & + & $\begin{array}{l}\text { adjusted proportion Q1-Q4 } \\
(95 \% \mathrm{Cl}): 0.33(0.26-0.40), 0.32 \\
(0.25-0.40), 0.48(0.39-0.57), \\
0.56(0.47-0.64)\end{array}$ \\
\hline \multirow[t]{2}{*}{ aHEI-2010 } & Biochemical pregnancy & Gaskins (2019) [48] & 357 women $^{\mathrm{a}}$ & no appreciable association & $\begin{array}{l}\text { adjusted proportion Q1-Q4 } \\
(95 \% \mathrm{Cl}): 0.62(0.54-0.69), 0.59 \\
(0.50-0.67), 0.53(0.44-0.61), \\
0.54(0.46-0.62)\end{array}$ \\
\hline & Clinical pregnancy & Gaskins (2019) [48] & 357 women $^{a}$ & no appreciable association & $\begin{array}{l}\text { adjusted proportion Q1-Q4 } \\
\text { (95\%Cl): } 0.55(0.47-0.63), 0.51 \\
(0.43-0.59), 0.50(0.42-0.59), \\
0.45(0.37-0.53)\end{array}$ \\
\hline
\end{tabular}

Live birth

Gaskins (2019) [48] 357 women $^{\mathrm{a}}$ no appreciable association adjusted proportion Q1-Q4 (95\%Cl): $0.44(0.36-0.52), 0.42$ $(0.34-0.50), 0.40(0.33-0.49)$, $0.37(0.29-0.45)$

'Fertility Diet'

Biochemical pregnancy Gaskins (2019) [48] 357 women $^{\text {a }}$ no appreciable association a

(justed proportion Q1-Q4 (95\%Cl): $0.54(0.46-0.62), 0.58$ $(0.50-0.66), 0.62(0.53-0.69)$, $0.54(0.45-0.63)$

Clinical pregnancy

Live birth

Biochemical pregnancy Vujkovik (2010) 161 couples -

[54]

\section{processed'}

Dutch 'preconception' diet Clinical pregnancy

'vegetable and Seafood' Clinical pregnancy

'Western'

Clinical pregnancy

'rice and miso soup'

Clinical pregnancy

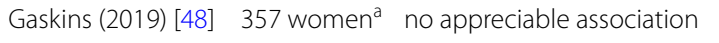

djusted proportion Q1-Q4

(95\%Cl): $0.45(0.41-0.56), 0.53$

(45-0.60), $0.52(0.44-0.61), 0.47$ (0.39-0.56)

Gaskins (2019) [48] 357 women $^{\mathrm{a}}$ no appreciable association adjusted proportion Q1-Q4 $(95 \% \mathrm{Cl}): 0.37(0.30-0.45), 0.42$ $(0.35-0.50), 0.42(0.34-0.50)$, $0.43(0.34-0.52)$

adjusted OR $(95 \% \mathrm{Cl})$ (ref not stated) (value provided to one decimal place in article): $0.8(0.6-1.0)$

adjusted OR (95\% Cl): 1.65 $(1.08-2.52)$

Twigt (2012) [53] 199 women +

Sugawa (2018) [51] 140 women no appreciable association adjusted OR Q1-Q4 (95\%Cl): 1.00 (ref) $0.46(0.14-1.53), 0.42$ $(0.13-1.43), 0.90(0.30-2.69)$

Sugawa (2018) [51] 140 women no appreciable association adjusted OR Q1-Q4 (95\%Cl): 1.00 (ref) $1.90(0.58-6.24), 1.38$ $(0.41-4.61), 0.84(0.23-3.11)$
Sugawa (2018) [51] 140 women no appreciable association adjusted OR Q1-Q4 (95\%Cl): 1.00 (ref), $1.78(0.58-6.77), 1.98$ (0.58-6.77), $0.72(0.18-2.93)$

$+=$ positive association

- = negative association.

a sample contributed 608 ART 'cycles' and adjustments were made for unbalanced study design (different number of cycles contributed per woman) 


\section{Dietary patterns with largely null associations with IVF outcomes \\ The aHEI-2010 diet and 'fertility diet'}

The aHEI-2010 diet and 'Fertility Diet' were examined alongside the MedDiet and 'profertility' diet in Gaskins, 2019. Higher adherence to the aHEI-2010 diet or the 'Fertility Diet' was not appreciably associated with biochemical pregnancy, clinical pregnancy, or live birth (aHEI-2010 diet probability of live birth as an adjusted proportion Q1 vs Q4 $(95 \% \mathrm{CI})=0.44(0.36-0.52), 0.37$ $(0.29-0.45)$ ) ('Fertility Diet' probability of live birth as an adjusted proportion Q1 vs Q4 $(95 \% \mathrm{CI})=0.37(0.30-$ 0.45), 0.43 (0.34-0.52)) [48] (Table 4). The 'Fertility Diet' is comprised of higher intake of monounsaturated fatty acids to trans-fat, vegetable protein, high-fat dairy, iron, and multivitamins; lower intake of animal protein and low-fat dairy; and lower glycemic load. The aHEI-2010 diet is comprised of higher intake of vegetables (excluding potatoes), fruit, whole grains, nuts and legumes, long chain omega-3 fats, polyunsaturated fat, and alcohol; and lower intake of sugar-sweetened beverages, fruit juice, red and processed meat, trans-fat, and sodium [48] (Table 2).

\section{'Vegetable and seafood', 'Western' and 'rice and miso soup' dietary patterns}

Like Twigt (2012), Sagawa (2018) examined the association between adherence to a 'healthier' dietary pattern, defined as 'high intake of fruit and vegetables and abundant nutrients', and IVF outcomes [51]. Sagawa identified three patterns of dietary intake in a cohort of 140 infertile Japanese women: a 'healthier' pattern called 'vegetable and seafood' with a high intake of vegetable, seafood, soy, and chicken; and two likely less healthy dietary patterns, 'Western' with a high intake of oil, meat, and chicken; and 'rice and miso soup' with a high intake of rice and miso soup (Table 2). Contrary to Twigt (2012), Sugawa (2018) found no association between higher adherence to a 'healthier' pattern and clinical pregnancy, confirmed by ultra sound 21 days after egg retrieval (vegetable and seafood adjusted $\mathrm{O} R$ per 1 category increase in adherence $=0.8595 \% \mathrm{CI}(0.67-1.39)$ ) ('Western' $=0.92$ 95\% CI $(0.63-1.36))$ (rice and miso soup $=0.9495 \% \mathrm{CI}$ (0.63-1.40)) (Table 4).

\section{'Health-conscious low processed' dietary pattern}

Vujkovik [54] examined a 'Mediterranean style' and 'health-conscious low processed' dietary pattern, within the same cohort of 161 couples. The 'health-conscious low processed' dietary pattern is defined as containing high intakes of fruits, vegetables, whole grains, fish, and legumes, but low intake of mayonnaise, snacks, and meat products (Table 2). Contrary to findings for the
'Mediterranean style' dietary pattern, a couple's higher adherence to a 'health-conscious low processed' dietary pattern was associated with reduced odds of biochemical pregnancy (adjusted OR 0.8 (95\% CI: 0.6-1.0) (Table 4). Vujkovik [54] attributes the difference in findings to higher intake of linoleic acid, a component found in vegetable oil, and higher levels of vitamin B6 found in the serum and follicular fluid of women with higher adherence to a 'Mediterranean style' dietary pattern.

\section{Study characteristics likely leading to increased heterogeneity Study population and exclusion criteria}

Studies were conducted in six countries: China, Japan, Greece, Italy, the Netherlands $(n=2)$, and U.S. (Supplement Table 2). Three studies excluded women based on underlying medical and/or reproductive conditions including; hypertension, endometriosis, or tubal factor infertility $[49,51,54]$. Two excluded older women (over 40 or 41) $[49,52]$, two excluded women based on treatment protocol $[49,52]$, and three studies contained a higher percentage of participants with male versus female factor infertility $[49,53,54]$. By exclusion criteria, one study each excluded women who did not undergo an ART treatment [48], did not undergo an embryo transfer [53], or became pregnant before treatment started [54].

\section{Dietary patterns and components}

Across studies, the exposure under investigation (dietary pattern) was selected using two different methods (Supplemental Table 2). In two studies, an $\alpha$-posteriori approach was utilized $[51,54]$. Results from participant questionnaires or FFQ were examined and the exposure was derived based on which dietary pattern best fit the data. In the remaining studies, investigators used a hypothesis driven $\alpha$-priori approach. An exposure was chosen before dietary intake information was obtained and a FFQ or questionnaire appropriate for the respective pattern administered.

No two studies included the same dietary components in their definitions of the MedDiet (Table 2). All MedDiet definitions included higher intake of seafood, legumes, fruits, and vegetables. Most included low consumption of meat $[48-50,52]$ and low to moderate (versus no or high) intake of alcohol [48-50, 54]. Definitions inconsistently included; whole grains, type of fats and oils, dairy, nuts, poultry, and potatoes (Table 2).

\section{Time period of exposure assessment}

All studies reporting the exposure window period asked participants about relatively recent dietary intake with exposure windows ranging from four weeks [54] to twelve months prior to exposure assessment $[48-50,52]$ (Supplemental Table 2). In Sugawa (2018), participants 
reported their current dietary intake during the month leading up to oocyte retrieval, and in Twigt (2012) the exposure window is not stated. In two studies, women were asked whether they had changed their diet during the exposure window and were excluded if they had made a change $[49,52]$. In the remaining studies, diet change during the exposure window was not reported $[48,50,51,53,54]$.

\section{Study end points and follow-up}

Study length varied from one month [51] to ten years [48] (Supplemental Table 2). Participants were followed until the occurrence of at least one of the following events: biochemical pregnancy, clinical pregnancy, or live birth; completion of a maximum of six medical stimulation 'cycles' or treatment cessation [48], one oocyte retrieval and the transfer of resulting fresh and/or frozen embryos (only cycle with 'best' outcome included in analysis) [50], one oocyte retrieval and transfer of only the first fresh embryo(s) $[49,51,53,54]$, or until study end date [52]. The maximum time period between the exposure assessment and reproductive outcome was not explicitly stated across studies, however likely ranged from weeks and months [48-54] to years $[48,50]$, and in the case of Gaskins and colleagues (2019), potentially up to ten years.

\section{Outcome definitions}

Outcomes were defined somewhat inconsistently (Supplemental Table 2). Four studies reported on biochemical pregnancy defined as a rise in serum 3 hCG 14-21 days after oocyte retrieval $[48,49]$, urine test 15 days after oocyte retrieval [54], and undefined in one [52]. Six studies reported on clinical pregnancy confirmed by ultrasound at $6-10$ weeks $[48-51,53]$, and undefined in one study [52]. Three studies reported the outcome of live birth, which was defined as birth of a neonate after 24 weeks in two studies [48, 49] and not defined in the third study [50].

\section{Study characteristics likely leading to methodological challenges \\ Exposure assessment}

All studies utilized questionnaires to assess exposure, with most utilizing a validated self-administered semiquantitative FFQ (number of items ranging from 6 to 131) $[48,49,51,54]$ (Supplemental Table 2). No questionnaire was validated prospectively in a population of women experiencing infertility and/or undergoing IVF treatment. In all studies, for exposure classification, participants were grouped into categories of adherence (e.g., low, intermediate, high) to the dietary pattern under investigation in relation to other participants' adherence based on questionnaire responses. In all studies, exposure used for analyses and covariates were assessed once at baseline and not reassessed during the follow up period for changes. Studies including participants who utilized cryopreserved embryos or oocytes did not assess exposure at both the time of cryopreservation and the time of attempted use/transfer into a uterus $[48,50]$.

\section{Timing of recruitment and exposure data collection}

It is unclear if studies included baseline data on the duration of the current pregnancy attempt. A portion of participants in three studies had undergone at least one prior IVF treatment cycle during the current pregnancy attempt at the time of recruitment $[48,50,54]$ while no participant had a previous IVF treatment in two studies $[49,51]$ (Supplemental Table 2). Four studies collected information on participants' 'duration of infertility' at the time of baseline data collection [49, 52-54]. In the two studies in which a range of data was provided, participants had a mean duration of 3 years $[49,52]$. Six studies collected exposure data subsequent to initial consultation for infertility; three at treatment initiation [48, 51, 52], two at the time of oocyte retrieval $[49,50]$ and one at the time of embryo transfer [54].

\section{Covariates collected for assessment of confounding}

Female age and body mass index (BMI) were the only covariates controlled for in all studies (Supplemental Table 2). All but one study controlled for energy intake and smoking [52]. 'Duration of infertility', previous use of ART, infertility diagnosis (male, female, unexplained), education, income, treatment protocol and use of ICSI, parity, physical activity, vitamin/supplement use, alcohol and caffeine intake, paternal covariates, and covariates related to mental health were inconsistently controlled for [48-54].

\section{Discussion}

Associations between dietary patterns and IVF outcomes

Nine different dietary patterns from seven observational studies were examined among participants. Higher adherence to the MedDiet, a Dutch 'preconception' diet, and a 'profertility' diet were associated with improvements in biochemical pregnancy, clinical pregnancy, or live birth in at least one study. Amongst studies of the MedDiet, findings were inconsistent and dose-response associations were only found in one study. Within the study, associations were modified by age and present only among women age $<35$ and only for the outcomes of clinical pregnancy and live birth. Although examined in one relatively small population, increased adherence to a 'profertility' diet was associated with improvements in biochemical pregnancy, clinical pregnancy, and live birth. Likewise, higher adherence to a Dutch 'preconception 
diet' was associated with improvements in clinical pregnancy in a single small study. The aHEI-2010 diet, 'Fertility Diet', 'health-conscious low processed' dietary pattern, 'vegetable and seafood' dietary pattern, 'Western' dietary pattern, and 'rice and miso soup' dietary pattern were not materially associated with improved IVF outcomes. Explanations for differences in findings across and within studies on the MedDiet put forth by study authors include the escalating and overshadowing influence of age on fertility [49], lack of accounting for dietary supplements [50], and insufficient statistical power [51]. Likewise, authors of studies investigating remaining dietary patterns hypothesize that differences may be attributed to intake of substances such as pesticides [48] and linoleic acid [54]. However, causative conclusions are difficult to draw due to the high degree of heterogeneity across studies and potential bias resulting from methodological issues which may mask true associations.

\section{Heterogeneity across studies}

Sources of heterogeneity included different study populations, dates, and length; selection of participants and dietary pattern under investigation; exposure window and assessment relative to the outcome; outcomes investigated and definitions; and control for potential confounders. However, differences in how the MedDiet was defined, geographic locations, and study end points make comparing studies especially difficult.

The MedDiet has over 34 definitions across the broader literature differing by a number of factors including constituent dietary components $[59,60]$. In this review, five different MedDiet definitions were used, one determined $\alpha$ posteriori, and some included and/or excluded individual dietary components that have been independently associated with reproductive outcomes [31]. Moderate intake (0.5-2 glasses per day) of alcohol is a common yet controversial component of the MedDiet [61-63]. There is uncertainty around the safety of women's alcohol consumption during conception and pregnancy [64-66], however alcohol was incorporated into almost all definitions of the MedDiet in this review. Due to the low number of studies using any one MedDiet definition, we cannot speculate on the extent to which definitional differences may have affected findings across studies. However, in future studies, it may be informative to compare analyses within a given population using different existing definitions of the MedDiet and prudent to consider excluding alcohol from future dietary pattern definitions used in studies on this topic.

Geographic location of studies may contribute to heterogeneity and affect observed associations across studies $[67,68]$. Studies examining the MedDiet were conducted in five different countries, two in Mediterranean regions. As studies on the MedDiet generally contain internal comparison groups and the range of adherence differs across geographic regions, it is difficult to appreciate how the same categories of dietary intake correlate across studies. Similarly, different populations may not contain enough heterogeneity in dietary intake to fully test some hypotheses $[37,69]$. In future studies, it may be useful to provide a population mean and range or clinically based cut points (when available), so that it is easier to understand how results may apply in different populations.

Lastly, study end points were heterogenous across studies. Ideally, in a study on IVF treatment, women would be followed for all pregnancy attempts until they achieved the outcome of interest or stopped treatment. Most studies on the MedDiet followed women for one fresh embryo transfer. While abbreviating the follow-up period simplifies the data collection and analysis, this strategy can oversimplify associations [70] and limit comparability. For instance, associations between exposure and the results from a single first fresh embryo transfer versus multiple embryo transfers or transfers with cryopreserved embryos, may differ. When placing findings into context, it may be helpful to limit comparisons to studies with similar end points so that women and clinicians can better interpret results.

\section{Methodological challenges}

Three key methodological challenges of existing studies include the inaccurate assessment of exposure, enrollment of women with previous pregnancy attempts, and lack of comprehensive control for confounding.

\section{Collecting accurate exposure information}

Information about the potential impact of diet, healthy eating and weight loss on fertility is widely available [7173]. Studies have reported that some women change their habits in response to unsuccessful pregnancy attempts [74-79] and that populations of women undergoing IVF treatment have a higher prevalence of disordered eating when compared with the general population [80-84].

Exposure in all studies was based on information from a single questionnaire or FFQ. However, the accuracy of FFQs and questionnaires can vary across populations [85, 86]. No study questionnaire was prospectively validated among women experiencing infertility and/or undergoing IVF treatment before use, potentially resulting in exposure misclassification. Exposure misclassification would likely attenuate associations toward the null as the outcomes was not known at the time of assessment. Even with a validated $F F Q$, collecting accurate information on exposure is difficult as FFQs are designed to approximate intake over a period of time. Few studies assessed if women changed their diet during the exposure window $[49,52]$ increasing risk for heterogeneity within categories of exposure. Future studies would benefit from FFQs 
prospectively validated in populations of women undergoing IVF and collecting data on any dietary changes during the exposure window.

\section{Enrollment of women with previous pregnancy attempts}

All studies recruited women seeking IVF treatment and it's unclear if studies collected data on number of previous pregnancy attempts. Women seek and receive IVF treatment after a different number of pregnancy attempts and two studies included women with prior IVF attempts $[87,88]$. Thus, cohorts likely contained samples with a heterogenous number of prior pregnancy attempts at baseline. If the dietary pattern under study is a cause of improved fertility, then women with higher adherence to the dietary pattern will have higher underlying fertility and will be less likely to be included in the study, resulting in a selection bias (left truncation) that could attenuate associations toward the null $[89,90]$. To minimize (but not eliminate) bias from left truncation, future studies examining associations between dietary patterns and IVF outcomes could, at the very least, enroll and follow women from their initial consult at an infertility treatment center.

If infertility or a previous unsuccessful IVF cycle caused a change in diet, then reverse causation could be a potential source of bias in studies that enroll infertile couples utilizing IVF treatment. Reverse causation usually occurs in studies when participants' knowledge of the outcome influences their exposure [91]. Although all exposure data was collected prior to the outcome, there is the potential for reverse causation if participants had related outcomes and believe their exposure may be related to these outcomes [23, 92, 93]. Women have reported using diet to enhance IVF treatment success since as early as 2001 $[73,75,94,95]$ and no data was collected in any study in this review regarding participants' knowledge of the associations between diet and reproductive outcomes. The potential for reverse causation could be assessed in future studies by collecting data on participants' knowledge of the potential associations between diet, fertility, and IVF outcomes, and if any change in diet was related to their knowledge.

\section{Controlling for confounding}

While all studies in this review collected data on potential confounders, it is difficult to anticipate and collect data on every possible confounder related to diet. Most authors acknowledge the potential for residual confounding. However, potentially important sources of residual confounding not addressed in most studies include male diet, which often mirrors female diet [96-99]; complementary and 'add-on' therapies, which may be used by women in conjunction with diet to enhance fertility [78,
100-105]; and weight loss [106, 107]. At a minimum, all studies should collect a broad range of data on potential confounders including demographic factors (e.g., race, ethnicity, age, and country of origin), socioeconomic position (e.g., education, occupation, income, and marital status), behavioral factors, lifestyle, anthropometrics, multivitamin use, medication use, and medical, and reproductive history. In addition, all studies should control for total energy intake to adjust for confounding, reduce measurement error, and account for differences in basal metabolic rate and body size.

\section{Limitations}

Limitations to our systematic review should be noted when considering its findings. Across the literature, no study investigated long-term dietary patterns, therefore results only reflect recent intake. We included only English language publications in our search and excluded studies with samples restricted to women who were overweight and/or diagnosed with PCOS. A prospective registration was not undertaken and a single author conducted the literature search and screen. A meta-analysis was not conducted due to the high degree of heterogeneity across studies and the low number of studies examining any one dietary pattern and any one outcome. We did not discuss potential limitations of different statistical approaches and some findings from included studies may be spurious. Conversely, strengths of our review include the systematic approach and focus on sources of heterogeneity and bias. Likewise, our review included all study dates during the literature search and all identified dietary patterns that fit the review criteria.

\section{Conclusions}

The literature on associations between female diet and fertility is rapidly expanding. This review adds to the current knowledge by highlighting: female dietary patterns that have been investigated for associations with IVF outcomes, ways in which studies differ, methodological challenges, and strategies that could be employed in future studies. Although some studies reported positive associations between female dietary patterns and IVF outcomes, causation cannot be assumed. Studies were potentially hindered by methodological challenges (misclassification of exposure, left truncation, and lack of comprehensive control for confounding) with an associated risk of bias. In particular, studies of the MedDiet were highly heterogenous in study population, methods, and findings, and remaining dietary patterns have each only been examined in single and relatively small populations of women. Future studies with rigorous and more uniform methodologies are needed to determine the association between female dietary patterns and IVF outcomes. At the clinical 
level, findings from this review do not support recommending any single dietary pattern for the purpose of improving pregnancy or live birth rates in women undergoing IVF treatment.

\begin{abstract}
Abbreviations
IVF: in vitro fertilization; ART: Assisted Reproductive Technology; ICSI: Intracytoplasmic Sperm Injection; ßhCG: beta Human Chorionic Gonadotrophin; PCOS: Polycystic Ovarian Syndrome; EARTH: the study of Environmental and Reproductive Health; MedDiet: Mediterranean Diet and 'Mediterranean style' Dietary pattern; aHEI-2010: alternate healthy eating index 2010; FFQ: Food Frequency Questionnaire; PDR: Preconception Dietary Risk Score.
\end{abstract}

\section{Supplementary Information}

The online version contains supplementary material available at https://doi. org/10.1186/s12937-021-00757-7.

Additional file 1. PRISMA 2009 Checklist.

Additional file 2: Supplementary Table 2. Characteristics of studies on female dietary patterns and IVF outcomes.

\section{Acknowledgements}

We would like to thank Wanda Anderson for her assistance with the literature search and Susan Kelly-Weeder for providing feedback on an early draft.

\section{Authors' contributions}

ES conceived the idea and design of the review. SKL and LAW refined and expanded the design. ES, SKL and LAW all contributed to the analysis and interpretation of results. ES wrote the manuscript with input from all authors. All authors read and approved the final manuscript.

\section{Funding}

No funding was received for this literature review.

\section{Availability of data and materials}

Not applicable.

\section{Declarations}

Ethics approval and consent to participate

Not applicable.

\section{Consent for publication}

Not applicable.

\section{Competing interests}

The authors declare that they have no competing interests.

\section{Author details}

'Boston College, Boston, USA. ${ }^{2}$ Boston University School of Public Health, Boston, USA.

Received: 21 December 2020 Accepted: 18 December 2021 Published online: 18 January 2022

\section{References}

1. Rutstein SO, Shah IH. Infecundity, infertility, and childlessness in developing countries. Demographic and Health Surveys (DHS) comparative reports no. 9 [Internet]. World Health Organization. World Health Organization; 2014. [cited 2022 Jan10]. Available from: https://www. who.int/reproductivehealth/publications/infertility/DHS_9/en/.

2. Thoma ME, MCLain AC, Louis JF, King RB, Trumble AC, Sundaram R, et al. The prevalence of infertility in the United States as estimated by the current duration approach and a traditional constructed approach. Fertil Steril. 2013;99(5):1324-31 e1. Available from: https://www.ncbi. nIm.nih.gov/pmc/articles/PMC3615032/. [cited 2019 Dec 10].

3. World Health Organization. Infertility [Internet]. World Health Organization. World Health Organization; 2019. [cited 2022 Jan 10]. Available from: https://www.who.int/health-topics/infertility\#tab=tab_3.

4. Reindollar RH, Regan MM, Neumann PJ, Levine B-S, Thornton KL, Alper $\mathrm{MM}$, et al. A randomized clinical trial to evaluate optimal treatment for unexplained infertility: the fast track and standard treatment (FASTT) trial. Fertil Steril. 2010;94(3):888-99 Available from: http://www.scien cedirect.com/science/article/pii/S0015028209008668. [cited 2020 Jun 26].

5. Olivius C, Friden B, Borg G, Bergh C. Why do couples discontinue in vitro fertilization treatment? a cohort study. Fertil Steril. 2004;81(2):258-61 Available from: http://www.sciencedirect.com/science/article/pii/S0015 028203028607. [cited 2020 Jun 6].

6. Roest J, van Heusden AM, Zeilmaker GH, Verhoeff A. Cumulative pregnancy rates and selective drop-out off patients in in-vitro fertilization treatment. Hum Reprod. 1998;13(2):339-41 Available from: http://acade mic.oup.com/humrep/article/13/2/339/875718. [cited 2020 Oct 28].

7. Afshin A, Sur PJ, Fay KA, Cornaby L, Ferrara G, Salama JS, et al. Health effects of dietary risks in 195 countries, 1990-2017: a systematic analysis for the Global Burden of Disease Study 2017. Lancet. 2019;393(10184):1958-72 Available from: https://www.thelancet.com/ journals/lancet/article/PIIS0140-6736(19)30041-8/abstract. [cited 2020 Dec 2].

8. Lim SS, Vos T, Flaxman AD, Danaei G, Shibuya K, Adair-Rohani H, et al. A comparative risk assessment of burden of disease and injury attributable to 67 risk factors and risk factor clusters in 21 regions, 1990-2010: a systematic analysis for the Global Burden of Disease Study 2010. Lancet. 2012:380(9859):2224-60 Available from: http://www.sciencedirect. com/science/article/pii/S0140673612617668. [cited 2020 Dec 2].

9. Amir AA, Kelly JM, Kleemann DO, Durmic Z, Blache D, Martin GB. Phytooestrogens affect fertilisation and embryo development in vitro in sheep. Reprod Fertil Dev. 2018;30(8):1109 Available from: http://www. publish.csiro.au/?paper=RD16481, [cited 2020 Jun 8].

10. Bandyopadhyay S, Chakrabarti J, Banerjee S, Pal AK, Goswami SK, Chakravarty BN, et al. Galactose toxicity in the rat as a model for premature ovarian failure: an experimental approach readdressed. Hum Reprod. 2003;18(10):2031-8 Available from: http://academic.oup.com/ humrep/article/18/10/2031/622732. [cited 2020 Jun 8].

11. Hwang CS, Kwak HS, Lim HJ, Lee SH, Kang YS, Choe TB, et al. Isoflavone metabolites and their in vitro dual functions: They can act as an estrogenic agonist or antagonist depending on the estrogen concentration. J Steroid Biochem Mol Biol. 2006;101(4)):246-53 Available from: http:// www.sciencedirect.com/science/article/pii/S0960076006001968. [cited 2020 Jun 8].

12. Kuiper GGJM, Lemmen JG, Carlsson B, Corton JC, Safe SH, van der Saag PT, et al. Interaction of Estrogenic Chemicals and Phytoestrogens with Estrogen Receptor $\beta$. Endocrinology. 1998;139(10):4252-63 Available from: http://academic.oup.com/endo/article/139/10/4252/2987100. [cited 2020 Jun 8].

13. Skaznik-Wikiel ME, Rudolph MC, Swindle DC, Polotsky AJ. Elevated serum levels of biologically active omega-3 fatty acids are associated with better ovarian reserve. Fertil Steril. 2016;106(3, Supplement):e66 Available from: http://www.sciencedirect.com/science/article/pii/S0015 028216616096. [cited 2020 Jun 8].

14. Swartz WJ, Mattison DR. Galactose inhibition of ovulation in mice. Fertil Steril. 1988;49(3):522-6.

15. Zhong R, Zhou D. Oxidative Stress and Role of Natural Plant Derived Antioxidants in Animal Reproduction. J Integr Agric. 2013;12(10):182638 Available from: http://www.sciencedirect.com/science/article/pii/ S2095311913604128. [cited 2020 Jun 8].

16. Brasky TM, Bethea TN, Wesselink AK, Wegienka GR, Baird DD, Wise LA Dietary Fat Intake and Risk of Uterine Leiomyomata: A Prospective Ultrasound Study. Am J Epidemiol. 2020; Available from: https://acade mic.oup.com/aje/advance-article/doi/10.1093/aje/kwaa097/5858261. [cited 2020 Oct 15].

17. Chavarro JE, Rich-Edwards JW, Rosner B, Willett WC. A prospective study of dairy foods intake and anovulatory infertility. Hum Reprod. 2007:22(5):1340-7. 
18. Harris HR, Eke AC, Chavarro JE, Missmer SA. Fruit and vegetable consumption and risk of endometriosis. Hum Reprod. 2018;33(4):715-27 Available from: http://academic.oup.com/humrep/article/33/4/715/ 4833874. [cited 2020 Oct 15].

19. Missmer SA, Chavarro JE, Malspeis S, Bertone-Johnson ER, Hornstein $\mathrm{MD}$, Spiegelman $\mathrm{D}$, et al. A prospective study of dietary fat consumption and endometriosis risk. Hum Reprod. 2010;25(6):1528-35 Available from: https://academic.oup.com/humrep/article/25/6/1528/2915756. [cited 2020 Aug 22]

20. Nodler JL, Harris HR, Chavarro JE, Frazier AL, Missmer SA. Dairy consumption during adolescence and endometriosis risk. Am J Obstet Gynecol. 2020;222(3):257.e1-257 e16.

21. Orta OR, Terry KL, Missmer SA, Harris HR. Dairy and related nutrient intake and risk of uterine leiomyoma: a prospective cohort study. Hum Reprod Oxf Engl. 2020;35(2):453-63.

22. Parazzini F, Chiaffarino F, Surace M, Chatenoud L, Cipriani S, Chiantera $V$, et al. Selected food intake and risk of endometriosis. Hum Reprod. 2004;19(8):1755-9 Available from: https://academic.oup.com/humrep/ article/19/8/1755/2356458. [cited 2020 Aug 22].

23. Wesselink AK, Hatch EE, Rothman KJ, Willis SK, Orta OR, Wise LA. Pesticide residue intake from fruits and vegetables and fecundability in a North American preconception cohort study. Environ Int 2020;139:105693 Available from: http://www.sciencedirect.com/scien ce/article/pii/S016041201934807X. [cited 2020 Jun 4].

24. Willis SK, Wise LA, Wesselink AK, Rothman KJ, Mikkelsen EM, Tucker KL, et al. Glycemic load, dietary fiber, and added sugar and fecundability in 2 preconception cohorts. Am J Clin Nutr. 2020; Available from: http:// academic.oup.com/ajcn/advance-article/doi/10.1093/ajcn/nqz312/ 5696748. [cited 2020 Jun 11].

25. Wise LA, Radin RG, Palmer JR, Kumanyika SK, Rosenberg L. A Prospective Study of Dairy Intake and Risk of Uterine Leiomyomata. Am J Epidemiol. 2010;171(2):221-32 Available from: https://academic.oup. com/aje/article/171/2/221/130461. [cited 2020 Aug 22].

26. Wise LA, Radin RG, Palmer JR, Kumanyika SK, Boggs DA, Rosenberg L. Intake of fruit, vegetables, and carotenoids in relation to risk of uterine leiomyomata. Am J Clin Nutr. 2011;94(6):1620-31 Available from: http:// academic.oup.com/ajcn/article/94/6/1620/4598201. [cited 2020 Oct 15].

27. Wise LA, Radin RG, Kumanyika SK, Ruiz-Narváez EA, Palmer JR, Rosenberg L. Prospective study of dietary fat and risk of uterine leiomyomata. Am J Clin Nutr. 2014;99(5):1105-16 Available from: http://academic. oup.com/ajcn/article/99/5/1105/4577416. [cited 2020 Oct 15].

28. Wise LA, Wesselink AK, Tucker KL, Saklani S, Mikkelsen EM, Cueto H, et al. Dietary Fat Intake and Fecundability in 2 Preconception Cohort Studies. Am J Epidemiol. 2018;187(1):60-74.

29. Wise LA, Wesselink AK, Mikkelsen EM, Cueto H, Hahn KA, Rothman KJ, et al. Dairy intake and fecundability in 2 preconception cohort studies. Am J Clin Nutr. 2017;105(1):100-10.

30. Chiu Y-H, Chavarro JE, Souter I. Diet and female fertility: doctor, what should I eat? and Sterility. 2018;110(4):560-9.

31. Gaskins AJ, Chavarro JE. Diet and fertility: a review. Am J Obstet Gynecol. 2018;218(4):379-89.

32. Messerlian C, Williams PL, Ford JB, Chavarro JE, Mínguez-Alarcón L, Dadd R, et al. The Environment and Reproductive Health (EARTH) Study: a prospective preconception cohort. Hum Reprod Open. 2018;2018(2) Available from: https://academic.oup.com/hropen/article/2018/2/ hoy001/4877108. [cited 2020 Mar 11].

33. Hu FB. Dietary pattern analysis: a new direction in nutritional epidemiology. Curr Opin Lipidol. 2002;13(1):3-9.

34. Kant AK. Dietary patterns and health outcomes. J Am Diet Assoc. 2004;104(4):615-35 Available from: http://www.sciencedirect.com/ science/article/pii/S0002822304000112. [cited 2020 May 24].

35. Tapsell LC, Neale EP, Satija A, Hu FB, et al. Adv Nutr. 2016;7(3):445-54 Available from: http://academic.oup.com/advances/article/7/3/445/ 4558132. [cited 2020 Aug 22].

36. Willett W. Nutritional epidemiology. 3rd ed. Oxford: Oxford University Press; 2013.

37. Barnard ND, Willett WC, Ding EL. The Misuse of Meta-analysis in Nutrition Research. JAMA. 2017;318(15):1435-1436. Available from: http://jaman etwork.com/journals/jama/fullarticle/2654401. [cited 2020 Jun 17]
38. Eysenck HJ. Meta-analysis squared_does it make sense? Am Psychol. 1995;50(2):110-1.

39. Moher D, Liberati A, Tetzlaff J, Altman DG, for the PRISMA Group. Preferred reporting items for systematic reviews and meta-analyses: the PRISMA statement. BMJ. 2009;339(jul21 1):b2535.

40. Broughton DE, Moley KH. Obesity and female infertility: potential mediators of obesity's impact. Fertil Steril. 2017;107(4):840-847. Available from: https://www.fertstert.org/article/S0015-0282(17)30060-2/ abstract. [cited 2019 Oct 21]

41. Johnson NP. No more surrogate end-points in randomised trials: The PCOSMIC trial protocol for women with polycystic ovary syndrome using metformin for infertility with clomiphene. Aust N Z J Obstet Gynaecol. 2006;46(2):141-5 Available from: http://www.embase.com/ search/results? subaction $=$ viewrecord\&from $=$ export\&id $=\mathrm{L} 43478416$.

42. Legro RS, Wu X, Barnhart KT, Farquhar C, Fauser BCJM, Mol B, et al. Improving the Reporting of Clinical Trials of Infertility Treatments (IMPRINT): modifying the CONSORT statement. Hum Reprod. 2014;29(10):2075-82 Available from: http://academic.oup.com/humrep/article/29/10/2075/650266. [cited 2020 May 24].

43. Messerlian C, Gaskins AJ. Epidemiologic Approaches for Studying Assisted Reproductive Technologies: Design, Methods, Analysis and Interpretation. Curr Epidemiol Rep. 2017;4(2):124-132. Available from: https://www.ncbi.nlm.nih.gov/pmc/articles/PMC5636007/. [cited 2020 Feb 5]

44. Zegers-Hochschild F, Adamson GD, Dyer S, Racowsky C, de Mouzon J, Sokol R, et al. The International Glossary on Infertility and Fertility Care, 2017. Hum Reprod. 2017;32(9):1786-801 Available from: http://acade mic.oup.com/humrep/article/32/9/1786/4049537. [cited 2020 Oct 28].

45. Scottish Intercollegiate Guidelines Network. Checklists. SIGN. 2012. Available from: https://testing36.scot.nhs.uk. [cited 2020 Aug 21]

46. Firns S, Cruzat VF, Keane KN, Joesbury KA, Lee AH, Newsholme $P$, et al. The effect of cigarette smoking, alcohol consumption and fruit and vegetable consumption on IVF outcomes: a review and presentation of original data. Reprod Biol Endocrinol RBE. 2015;16(13):134.

47. Jahangirifar M, Taebi M, Nasr-Esfahani MH, Askari G. Dietary Patterns and The Outcomes of Assisted Reproductive Techniques in Women with Primary Infertility: A Prospective Cohort Study. Int J Fertil Steril. 2019:12(4):316-23.

48. Gaskins AJ, Nassan FL, Chiu Y-H, Arvizu M, Williams PL, Keller MG, et al. Dietary patterns and outcomes of assisted reproduction. Am J Obstet Gynecol. 2019;220(6):567 e1-567.e18.

49. Karayiannis D, Kontogianni MD, Mendorou C, Mastrominas M, Yiannakouris N. Adherence to the Mediterranean diet and IVF success rate among non-obese women attempting fertility. Hum Reprod Oxf Engl. 2018;33(3):494-502 Available from: https://www.embase.com/search/ results?subaction=viewrecord\&id $=$ L621082213\&from=export.

50. Ricci E, Bravi F, Noli S, Somigliana E, Cipriani S, Castiglioni M, et al. Mediterranean diet and outcomes of assisted reproduction: an Italian cohort study. Am J Obstet Gynecol. 2019;221(6):627.e1-627.e14.

51. Sugawa M, Okubo H, Sasaki S, Nakagawa Y, Kobayashi T, Kato K. Lack of a meaningful association between dietary patterns and in vitro fertilization outcome among Japanese women. Reprod Med Biol. 2018 Oct;17(4):466-73.

52. Sun H, Lin Y, Lin D, Zou C, Zou X, Fu L, et al. Mediterranean diet improves embryo yield in IVF: a prospective cohort study. Reprod Biol Endocrinol. 2019;17(1):73

53. Twigt JM, Bolhuis MEC, Steegers EAP, Hammiche F, van Inzen WG, Laven JSE, et al. The preconception diet is associated with the chance of ongoing pregnancy in women undergoing IVF/ICSI treatment. Hum Reprod Oxf Engl. 2012;27(8):2526-31.

54. Vujkovic M, de Vries JH, Lindemans J, Macklon NS, van der Spek PJ, Steegers EAP, et al. The preconception Mediterranean dietary pattern in couples undergoing in vitro fertilization/intracytoplasmic sperm injection treatment increases the chance of pregnancy. Fertil Steril. 2010;94(6):2096-101.

55. Panagiotakos DB, Pitsavos C, Stefanadis C. Dietary patterns: A Mediterranean diet score and its relation to clinical and biological markers of cardiovascular disease risk. Nutr Metab Cardiovasc Dis. 2006;16(8):559_ 68 Available from: http://www.sciencedirect.com/science/article/pii/ S093947530500178X. [cited 2020 Dec 6]. 
56. Trichopoulou A, Costacou T, Bamia C, Trichopoulos D. Adherence to a Mediterranean Diet and Survival in a Greek Population. N Engl J Med. 2003;348(26):2599-608. https://doi.org/10.1056/NEJMoa025039 [cited 2020 Dec 6].

57. Willett WC, Sacks F, Trichopoulou A, Drescher G, Ferro-Luzzi A, Helsing E, et al. Mediterranean diet pyramid: a cultural model for healthy eating. Am J Clin Nutr. 1995;61 (6):1402S-6S Available from: http://academic. oup.com/ajcn/article/61/6/1402S/4651234. [cited 2020 Dec 6].

58. CDC. National Summary Report | 2016 ART Report | Division of Reproductive Health |CDC. 2018. Available from: https://www.cdc.gov/art/ reports/2016/national-summary.html. [cited 2020 Nov 18]

59. Bach A, Serra-Majem L, Carrasco JL, Roman B, Ngo J, Bertomeu I, et al. The use of indexes evaluating the adherence to the Mediterranean diet in epidemiological studies: a review. Public Health Nutr. 2006;9(1a):13246 Available from: http://www.cambridge.org/core/journals/publichealth-nutrition/article/use-of-indexes-evaluating-the-adherence-tothe-mediterranean-diet-in-epidemiological-studies-a-review/9BDC2 AC49E96699F0A9BA39568858C16. [cited 2020 Aug 27].

60. Galbete C, SchwingshackI L, Schwedhelm C, Boeing H, Schulze MB. Evaluating Mediterranean diet and risk of chronic disease in cohort studies: an umbrella review of meta-analyses. Eur J Epidemiol. 2018;33(10):909-31 Available from: https://doi.org/10.1007/s10654018-0427-3. [cited 2020 Aug 27].

61. Giacosa A, Barale R, Bavaresco L, Faliva MA, Gerbi V, Vecchia CL, et al. Mediterranean Way of Drinking and Longevity. Crit Rev Food Sci Nutr. 2016;56(4):635-40 Available from: https://doi.org/10.1080/10408398. 2012.747484. [cited 2020 Aug 27].

62. Morales G, Martínez-González MA, Barbería-Latasa M, Bes-Rastrollo M, Gea A. Mediterranean diet, alcohol-drinking pattern and their combined effect on all-cause mortality: the Seguimiento Universidad de Navarra (SUN) cohort. Eur J Nutr [Internet]. 2020. [cited 2020 Aug 27]; Available from: https://doi.org/10.1007/s00394-020-02342-w.

63. Rimm EB, Ellison RC. Alcohol in the Mediterranean diet. Am J Clin Nutr. 1995;61 (6):1378S-82S Available from: http://academic.oup.com/ajcn/ article/61/6/1378S/4651226. [cited 2020 Aug 27].

64. Henriksen TB, Hjollund NH, Jensen TK, Bonde JP, Andersson A-M Kolstad $\mathrm{H}$, et al. Alcohol Consumption at the Time of Conception and Spontaneous Abortion. Am J Epidemiol. 2004;160(7):661-7 Available from: https://academic.oup.com/aje/article/160/7/661/136529. [cited 2020 Aug 29].

65. Mattson SN, Schoenfeld AM, Riley EP. Teratogenic Effects of Alcohol on Brain and Behavior. Alcohol Res Health. 2001;25(3):185-91 Available from: https://www.ncbi.nlm.nih.gov/pmc/articles/PMC6707166/. [cited 2020 Aug 29].

66. Salihu HM, Kornosky JL, Lynch O, Alio AP, August EM, Marty PJ. Impact of prenatal alcohol consumption on placenta-associated syndromes. Alcohol. 2011:45(1):73-9 Available from: http://www.sciencedirect. com/science/article/pii/S0741832910000613. [cited 2020 Aug 29].

67. Kaaks R, Riboli E. The role of multi-centre cohort studies in studying the relation between diet and cancer. Cancer Lett. 1997;114(1):263-70 Available from: http://www.sciencedirect.com/science/article/pii/S0304 383597046788. [cited 2020 Aug 28].

68. Rosato V, Temple NJ, La Vecchia C, Castellan G, Tavani A, Guercio V. Mediterranean diet and cardiovascular disease: a systematic review and meta-analysis of observational studies. Eur J Nutr. 2019;58(1):173-91 Available from: https://doi.org/10.1007/s00394-017-1582-0. [cited 2020 Aug 22].

69. Wallström P, Sonestedt E, Hlebowicz J, Ericson U, Drake I, Persson M, et al. Dietary fiber and saturated fat intake associations with cardiovascular disease differ by sex in the Malmö Diet and Cancer Cohort: a prospective study. PloS One. 2012;7(2):e31637.

70. Dodge LE, Farland LV, Correia KF, Missmer SA, Seidler EA, Wilkinson J, et al. Choice of statistical model in observational studies of ART. Hum Reprod. 2020; Available from: http://academic.oup.com/humrep/advan ce-article/doi/10.1093/humrep/deaa050/5839889. [cited 2020 Jun 27].

71. Backhausen MG, Ekstrand M, Tydén T, Magnussen BK, Shawe J, Stern J, et al. Pregnancy planning and lifestyle prior to conception and during early pregnancy among Danish women. Eur J Contracept Reprod Health Care. 2014;19(1):57-65 Available from: http://www.tandfonline. com/doi/full/10.3109/13625187.2013.851183. [cited 2020 May 28].
72. Chavarro J. The fertility diet groundbreaking research reveals natural ways to boost ovulation \& improve your chances of getting pregnant. New York: McGraw-Hill; 2008. p. x+277.

73. Sacha CR, Page CM, Goldman RH, Ginsburg ES, Zera CA. Are women with obesity and infertility willing to attempt weight loss prior to fertility treatment? Obes Res Clin Pract. 2018;12(1):125-8 Available from: http://www.sciencedirect.com/science/article/pii/S1871403X17301369. [cited 2019 Dec 29].

74. Armour M, Sinclair J, Chalmers KJ, Smith CA. Self-management strategies amongst Australian women with endometriosis: a national online survey. BMC Complement Altern Med. 2019;19(1):-17 Available from: https://doi.org/10.1186/s12906-019-2431-x. [cited 2020 Jun 20].

75. Coulson C, Jenkins J. Complementary and alternative medicine utilisation in NHS and private clinic settings: a United Kingdom survey of 400 infertility patients. J Exp Clin Assist Reprod. 2005;2:-5 Available from: https://www.ncbi.n/m.nih.gov/pmc/articles/PMC1084360/. [cited 2020 Aug 20].

76. Domar AD, Conboy L, Denardo-Roney J, Rooney KL. Lifestyle behaviors in women undergoing in vitro fertilization: a prospective study. Fertil Steril. 2012;97(3):697-701 e1. Available from: http://www.sciencedirect. com/science/article/pii/S0015028211028640. [cited 2020 Jun 28].

77. Lum KJ, Sundaram R, Buck Louis GM. Women's lifestyle behaviors while trying to become pregnant: evidence supporting preconception guidance. Am J Obstet Gynecol. 2011;205(3):203 e1-203.e7. Available from: http://www.sciencedirect.com/science/article/pii/S0002937811005163. [cited 2020 Sep 27]

78. Stankiewicz M, Smith C, Alvino H, Norman R. The use of complementary medicine and therapies by patients attending a reproductive medicine unit in South Australia: A prospective survey. Aust N Z J Obstet Gynaecol. 2007;47(2):145-9 Available from: http://obgyn.onlinelibrary.wiley. com/doi/abs/10.1111/j.1479-828X.2007.00702.x. [cited 2020 Jun 6].

79. Wise LA, Wesselink AK, Hatch EE, Weuve J, Murray EJ, Wang TR, et al. Changes in behavior with increasing pregnancy attempt time: a prospective cohort study. Epidemiology. 2020;31(5) Available from: https:// journals.Iww.com/10.1097/EDE.0000000000001220. [cited 2020 Jun 26].

80. Cousins A, Freizinger M, Duffy ME, Gregas M, Wolfe BE. Self-report of eating disorder symptoms among women with and without infertility. J Obstet Gynecol Neonatal Nurs JOGNN NAACOG. 2015;44(3):380-8 Available from: http://www.embase.com/search/results?subaction=vie wrecord\&from $=$ export\&id $=\llcorner 613661093$.

81. Freizinger M, Franko DL, Dacey M, Okun B, Domar AD. The prevalence of eating disorders in infertile women. Fertil Steril. 2010;93(1):72-8 Available from: http://www.sciencedirect.com/science/article/pii/S0015 02820804048X. [cited 2020 May 27].

82. Greenwood EA, Pasch LA, Cedars MI, Huddleston HG. Obesity and depression are risk factors for future eating disorder-related attitudes and behaviors in women with polycystic ovary syndrome. Fertil Steril. 2020;113(5):1039-49 Available from: http://www.sciencedirect.com/ science/article/pii/S0015028220300170. [cited 2020 Jul 5].

83. Stewart DE, Robinson E, Goldbloom DS, Wright C. Infertility and eating disorders. Am J Obstet Gynecol. 1990;163(4 Pt 1):1196-9.

84. Sylvester C, Menke M, Lopa S, Gopalan P. Disordered eating and distress in women seeking in vitro fertilization. J Psychosom Res. 2020;1 128:109880 Available from: http://www.sciencedirect.com/scien ce/article/pii/S0022399919309730. [cited 2020 Jan 10].

85. Cade J, Thompson R, Burley V, Warm D. Development, validation and utilisation of food-frequency questionnaires - a review. Public Health Nutr. 2002;5(4):567-87 Available from: http://www.cambridge.org/ core/journals/public-health-nutrition/article/development-validationand-utilisation-of-foodfrequency-questionnaires-a-review/463EFE9970 053E8BD922CC88F52E6244. [cited 2020 Apr 29].

86. Thompson FE, Byers T. Dietary Assessment Resource Manual. J Nutr. 1994;124(suppl_11):2245s-317s Available from: https://academic.oup. com/jn/article/124/suppl_11/2245s/4730326. [cited 2020 Jun 1].

87. Jain T. Socioeconomic and racial disparities among infertility patients seeking care. Fertil Steril. 2006;85(4):876-81 Available from: http://www. sciencedirect.com/science/article/pii/S0015028205043256. [cited 2020 Aug 28].

88. Missmer SA, Seifer DB, Jain T. Cultural factors contributing to health care disparities among patients with infertility in Midwestern United States. 
Fertil Steril. 2011;95(6):1943-9 Available from: http://www.sciencedirect. com/science/article/pii/S0015028211003372. [cited 2020 Aug 28].

89. Eijkemans MJC, Leridon H, Keiding N, Slama R. A Systematic Comparison of Designs to Study Human Fecundity: Epidemiology. 2019;30(1):120-9 Available from: http://journals.Iww.com/00001648201901000-00016. [cited 2020 Jun 28].

90. Schisterman EF, Cole SR, Ye A, Platt RW. Accuracy Loss Due to Selection Bias in Cohort Studies with Left Truncation. Paediatr Perinat Epidemiol. 2013;27(5):491-502 Available from: http://onlinelibrary.wiley.com/doi/ abs/10.1111/ppe.12073. [cited 2020 Jun 1]

91. Rothman KJ, Greenland S, Lash TL. Modern Epidemiology. 3rd ed. Philadelphia: Lippincott Williams \& Wilkins; 2008.

92. Cnattingius S, Akre O, Lambe M, Ockene J, Granath F. Will an adverse pregnancy outcome influence the risk of continued smoking in the next pregnancy? Am J Obstet Gynecol. 2006;195(6):1680-6 Available from: http://www.sciencedirect.com/science/article/pii/S000293780 6008301. [cited 2020 Jun 4].

93. Tran DT, Roberts $C L$, Jorm $L R$, Seeho $S$, Havard A. Change in smoking status during two consecutive pregnancies: a population-based cohort study. BJOG Int J Obstet Gynaecol. 2014;121(13):1611-20 Available from: http://obgyn.onlinelibrary.wiley.com/doi/abs/10.1111/1471-0528. 12769. [cited 2020 Jun 4].

94. Porter M, Bhattacharya S. Helping themselves to get pregnant: a qualitative longitudinal study on the information-seeking behaviour of infertile couples. Hum Reprod. 2008;23(3):567-72 Available from: http:// academic.oup.com/humrep/article/23/3/567/2914103. [cited 2020 Jun 1].

95. Rossi BV, Bressler LH, Correia KF, Lipskind S, Hornstein MD, Missmer SA. Lifestyle and in vitro fertilization: what do patients believe? Fertil Res Pract. 2016;2(1):11 Available from: https://doi.org/10.1186/s40738-0160026-5. [cited 2020 Apr 18].

96. Aly JM, Polotsky AJ. Paternal Diet and Obesity: Effects on Reproduction. Semin Reprod Med. 2017;35(4):313-7.

97. Cheng PJ, Pastuszak AW, Hotaling JM. Is it time to start folate supplementation in men? The effect of paternal folate status on embryonic growth. and Sterility. 2019;111(2):251-2 Available from: http://www. embase.com/search/results?subaction=viewrecord\&from=export\& $i d=L 2001414170$.

98. Marchetti F. How do paternal life style and environmental exposures impact on sperm and early embryos? Birth Defects Res Part - Clin Mol Teratol. 2011;91(5):324.

99. Oostingh EC, de Vos I, Ham AC, Brouwer-Brolsma EM, Willemsen SP, Eggink AJ, et al. No independent associations between preconception paternal dietary patterns and embryonic growth; the Predict Study. Clin Nutr. 2019;38(5):2333-41.

100. Kissin DM, Kawwass JF, Monsour M, Boulet SL, Session DR, Jamieson DJ. Assisted hatching: trends and pregnancy outcomes, United States, 2000-2010. Fertil Steril. 2014;102(3):795-801 Available from: http:// www.sciencedirect.com/science/article/pii/S0015028214005469. [cited 2020 Jun 6$]$

101. Lensen S, Shreeve N, Barnhart KT, Gibreel A, Ng EHY, Moffett A. In vitro fertilization add-ons for the endometrium: it doesn't add-up. Fertil Steril. 2019;112(6):987-93 Available from: http://www.sciencedirect.com/ science/article/pii/S0015028219324811. [cited 2020 Jan 16].

102. Rayner J-A, Willis K, Burgess R. Women's use of complementary and alternative medicine for fertility enhancement: a review of the literature. J Altern Complement Med NY N. 2011 Aug;17(8):685-90.

103. Smith JF, Eisenberg ML, Millstein SG, Nachtigall RD, Shindel AW, Wing $\mathrm{H}$, et al. The use of complementary and alternative fertility treatment in couples seeking fertility care: data from a prospective cohort in the United States. Fertil Steril. 2010;93(7):2169-74 Available from: http:// www.sciencedirect.com/science/article/pii/S001502821000347X. [cited 2020 Jun 20].

104. Spencer EA, Mahtani KR, Goldacre B, Heneghan C. Claims for fertility interventions: a systematic assessment of statements on UK fertility centre websites. BMJ Open. 2016;6(11) Available from: https://bmjopen. bmj.com/content/6/11/e013940. [cited 2020 Jan 16].

105. de Lacey SL, Sanderman E, Smith CA. Acupuncture in reproductive medicine: the motivations of infertile women to participate in a randomised controlled trial. J Psychosom Obstet Gynaecol. 2018;39(2):112-20.
106. Chavarro JE, Ehrlich S, Colaci DS, Wright DL, Toth TL, Petrozza JC, et al. Body mass index and short-term weight change in relation to treatment outcomes in women undergoing assisted reproduction. Fertil Steril. 2012;98(1):109-16 Available from: http://www.sciencedirect.com/ science/article/pii/S001502821200444X. [cited 2020 Aug 29].

107. Moran L, Tsagareli V, Norman R, Noakes M. Diet and IVF pilot study: Short-term weight loss improves pregnancy rates in overweight/obese women undertaking IVF. Aust N Z J Obstet Gynaecol. 2011;51(5):455-9 Available from: http://obgyn.onlinelibrary.wiley.com/doi/abs/10.1111/j. 1479-828X.2011.01343.x. [cited 2020 Aug 29].

\section{Publisher's Note}

Springer Nature remains neutral with regard to jurisdictional claims in published maps and institutional affiliations.
Ready to submit your research? Choose BMC and benefit from:

- fast, convenient online submission

- thorough peer review by experienced researchers in your field

- rapid publication on acceptance

- support for research data, including large and complex data types

- gold Open Access which fosters wider collaboration and increased citations

- maximum visibility for your research: over $100 \mathrm{M}$ website views per year

At BMC, research is always in progress.

Learn more biomedcentral.com/submissions 